\title{
Common-mode resonances in ultra wide band connected arrays of dipoles : measurements from the demonstrator and exit strategy
}

Citation for published version (APA):

Cavallo, D., Neto, A., \& Gerini, G. (2009). Common-mode resonances in ultra wide band connected arrays of dipoles : measurements from the demonstrator and exit strategy. In Proceedings of 11th international conference on Electromagnetics in Advanced Applications (ICEAA '09), 14-18 September 2009, Turin, Italy (pp. 435-438). Institute of Electrical and Electronics Engineers. https://doi.org/10.1109/ICEAA.2009.5297402

DOI:

10.1109/ICEAA.2009.5297402

Document status and date:

Published: 01/01/2009

Document Version:

Publisher's PDF, also known as Version of Record (includes final page, issue and volume numbers)

Please check the document version of this publication:

- A submitted manuscript is the version of the article upon submission and before peer-review. There can be important differences between the submitted version and the official published version of record. People interested in the research are advised to contact the author for the final version of the publication, or visit the $\mathrm{DOI}$ to the publisher's website.

- The final author version and the galley proof are versions of the publication after peer review.

- The final published version features the final layout of the paper including the volume, issue and page numbers.

Link to publication

\footnotetext{
General rights

- You may freely distribute the URL identifying the publication in the public portal. follow below link for the End User Agreement:

www.tue.nl/taverne

Take down policy

If you believe that this document breaches copyright please contact us at:

openaccess@tue.nl

providing details and we will investigate your claim.
}

Copyright and moral rights for the publications made accessible in the public portal are retained by the authors and/or other copyright owners and it is a condition of accessing publications that users recognise and abide by the legal requirements associated with these rights.

- Users may download and print one copy of any publication from the public portal for the purpose of private study or research.

- You may not further distribute the material or use it for any profit-making activity or commercial gain

If the publication is distributed under the terms of Article $25 \mathrm{fa}$ of the Dutch Copyright Act, indicated by the "Taverne" license above, please 


\title{
Common-Mode Resonances in Ultra Wide Band Connected Arrays of Dipoles: Measurements from the Demonstrator and Exit Strategy
}

\author{
D. Cavallo ${ }^{1,2}$ \\ A. Neto $^{3}$ \\ G. Gerini ${ }^{4}$
}

\begin{abstract}
A 6-9 GHz prototype array of dual-polarized connected dipoles has been manufactured. The array is composed by two orthogonal sets of $8 \times 8$ elements for each polarization (128), arranged in an egg-crate configuration. Preliminary measurements highlighted the presence of unpredicted common-mode resonances excited in the vertical feeding lines. An analysis of the common-mode excitation is carried out and exit strategies for a design of a resonance-free connected array are presented.
\end{abstract}

\section{INTRODUCTION}

The realization of wide-band, wide-scanning angle, phased arrays with good cross-polarization performance has been the object of many recent investigations. Although tapered slot antennas have very broad bandwidth, they are known to produce high cross-polarization components, especially in the diagonal cuts $\left(45^{\circ}\right),[1]$. On the other hand, conventional phased array based on printed radiating elements can achieve only moderate bandwidths $(\sim 25 \%)$, [2]-[4]. Therefore, a novel trend in this field is the use of connected arrays, i.e. arrays of long dipoles or slots periodically fed, in order to approximate Wheeler's continuous current sheet [5]. This concept was originally proposed by Hansen, [6], and further theoretically developed in [7], showing the wideband characteristic of such arrays. Thanks to the planarity of the radiators, the low cross-polarization level is among the most important features of such antenna solutions.

The first practical demonstration of a planar connected array antenna was given in [8]. This consisted in a connected array of slots in the UHF band, with good performance observed for broadside radiation. In [9], scanning performance of connected array was investigated for the first time and a theoretical design of a connected dipole array was presented, with $40 \%$ relative bandwidth and wide scan capability, up to 45 degrees in all the azimuth planes.

This paper reports the development of a dualpolarized phased array of connected dipoles, in the operational frequency band 6-9 GHz. Preliminary measurements highlighted an unpredicted problem with the performance, associated with commonmode resonances on the vertical feeding lines. The array element is fed via balanced lines, which can support both differential (desired) and common (undesired) currents. From an analysis of the common-mode, it appears that the resonance condition depends on both the length of the lines and the periodicity of the array. While common-mode propagation might be not directly observable from the matching performance of the array, it is always visible in form of high level of cross polarization when scanning on the diagonal plane $\left(\varphi=45^{\circ}\right)$. Due to the electrical connection of the elements, standard wideband baluns are not effective in a connected array. Therefore, a novel type of Printed Circuit Board (PCB) transformers is proposed as a valid solution for the design a resonance-free connected dipole array.

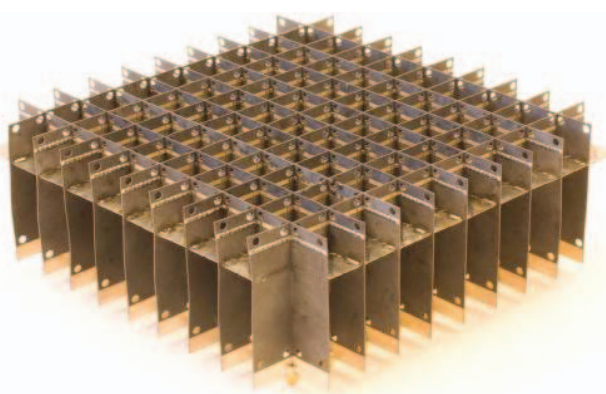

Fig. 1: Prototype array.

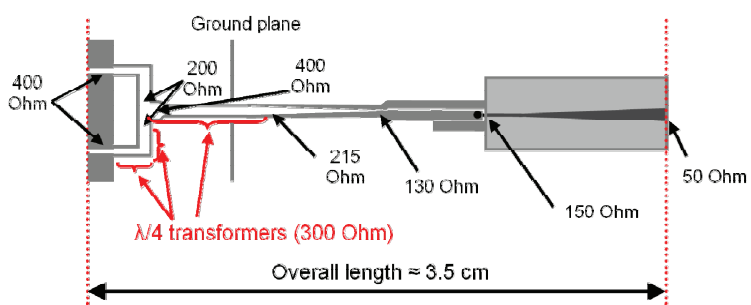

Fig. 2: Feeding lines of the array element, with impedance transformation from 400 to $50 \mathrm{Ohms}$.

\footnotetext{
${ }^{1}$ TNO Defence, Security and Safety, Oude Waalsdorperweg 63, 2597 AK, The Hague, The Netherlands, e-mail: daniele.cavallo@tno.nl, tel.: +31 70 3740249, fax: +31 703740653 .

${ }^{2}$ Eindhoven University of Technology, Den Dolech 2, 5600 MB, Eindhoven, The Netherlands.

${ }^{3}$ TNO Defence, Security and Safety, Oude Waalsdorperweg 63, 2597 AK, The Hague, The Netherlands, e-mail: andrea . neto@tno.nl, tel.: +31 70 3740582, fax: +31 703740653 .

${ }^{4}$ TNO Defence, Security and Safety, Oude Waalsdorperweg 63, 2597 AK, The Hague, The Netherlands, e-mail: giampiero.gerinietno.nl, tel.: +31 70 3740581, fax: +31 703740653
} 


\section{PROTOTYPE ARRAY}

The prototype array is shown in Fig. 1. The dipoles are printed on one side of a low permittivity $\left(\varepsilon_{r}=2.2\right)$ thin Duroid substrate, and electrically connected to form a unique long dipole periodically fed. The element spacing is $15.52 \mathrm{~mm}$, which is about half wavelength at $9 \mathrm{GHz}$. The impedance transformation from the wave impedance of the free space, 377 Ohms, at the aperture level, to $50 \mathrm{Ohms}$ at the connector, is performed with two wavelengths long transmission lines, printed on vertical printed circuit boards in a egg-crate configuration (Fig. 2). The transition from coplanar strip-lines (CPS) to coplanar waveguide (CPW) and then to microstrip (MS) performs the balanced to unbalanced conversion, together with a wideband impedance transformation. A double feed configuration in each periodic cell has been adopted in order to decrease the reactive capacitance associated with the feeding gaps. This arrangement of the feeding lines, implemented with a CPS power divider (Fig. 2), was shown to improve the bandwidth of the array, [9]. A ground plane is included at a height of approximately $0.3 \lambda_{0}$ (with $\lambda_{0}$ being the wavelength at $9 \mathrm{GHz}$ ) from the centre of the dipole, acting as a backing reflector.

Fig. 3 shows the active reflection coefficient of a central port of the finite array prototype when scanning toward broadside. From the measured curves, two unexpected resonance were observed at about $7 \mathrm{GHz}$ and $8.5 \mathrm{GHz}$. Triggered by such observation, full-wave simulations of the entire structure including the feeding network have been performed, for the first time. The comparison between simulations and measurements is relatively good, indicating that the numerical tools are able to efficiently describe the wave phenomena in place. Note that the measurements include the summation of all significant co-polarized $\mathrm{S}$ parameters for the investigated port, while the equivalent simulations are performed using the full wave simulator tool CST Microwave Studio and account for the entire finite array $(8 \times 8$ elements $)$.

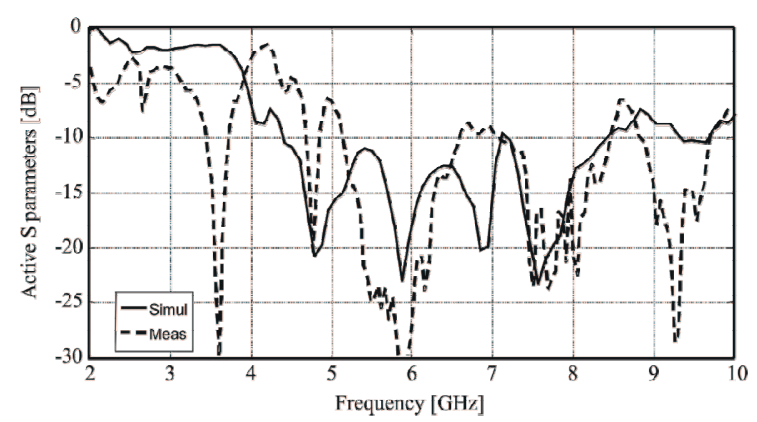

Fig. 3: Active reflection coefficient of a central element of the finite array.
In order to analyse the nature of such resonances, further simulations were carried out assuming an infinite periodic array analysis. The reflection coefficient in the presence of the feeding lines was significantly different from those that were simulated in the design phase without the inclusion of the long matching network. In Fig. 4, the simulated active reflection coefficient when the array is radiating toward $\theta=0^{\circ}$ and $\phi=0^{\circ}$ is reported. It is apparent that the array is completely mismatched at 5.25 and $7 \mathrm{GHz}$. At those frequencies, the simulations explicitly show the coexistence of common and differential modes in the long transmission lines. In Fig. 5, a schematic view of the electric current distribution along the feeding lines shows common mode propagation at $7 \mathrm{GHz}$, in correspondence of the resonance, while at $8 \mathrm{GHz}$ designed differential mode is dominant. It should be noted that these resonances are sharp and the radiation patterns, not reported here for brevity, do not indicate polarization degradation. However, the same simulations realized for the array radiating toward $\theta=$ $45^{\circ}$ and $\phi=45^{\circ}$ also show significant increases of the cross-polarized field levels. In practice, the scanning performance of the prototype array is limited by common modes excited in the vertical feeding lines. Needless to say that the infinite array configurations, while of great help in understanding the physics, overestimate the coherence of these standing waves, which are much less strong in a finite array (Fig. 3).

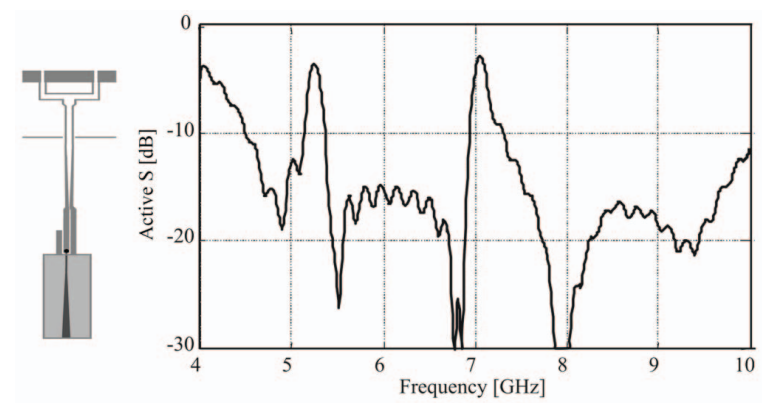

Fig. 4: Active reflection coefficient for an infinite array when radiating toward $\theta=0^{\circ}$ and $\varphi=0^{\circ}$.

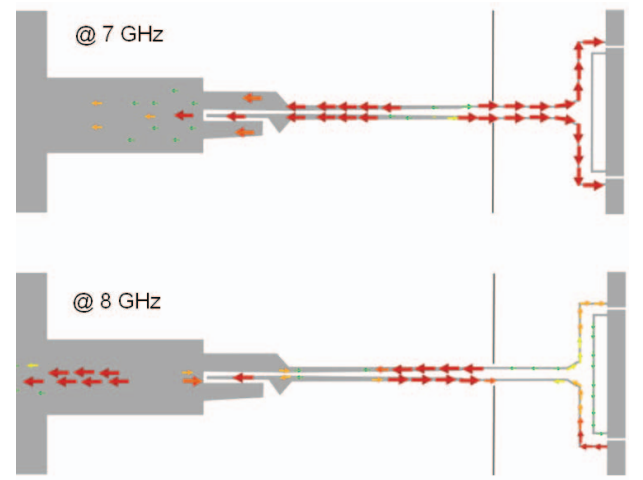

Fig. 5: Surface current distribution at 7 and $8 \mathrm{GHz}$. 


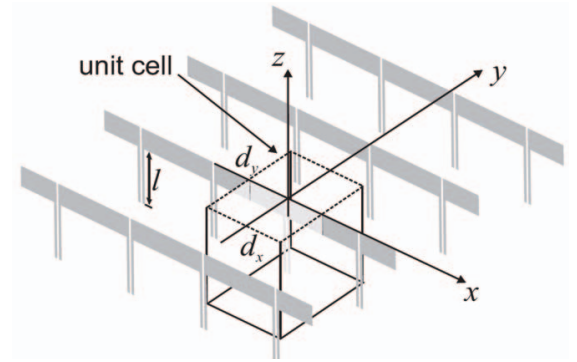

Figure 6: Geometry of a two dimensional array of dipoles fed by CPS lines.

\section{COMMON-MODE ANALYSIS}

In order to analyse the common-mode resonance, let us consider the simplified case of an infinite twodimensional array of dipoles with periodicity $d_{x}$ and $d_{y}$, as shown in Fig. 6. The array elements are fed by CPS lines, whose length is equal to $l$. For sake of generality, no backing reflector is introduced. However, typically connected arrays involve the presence of a backing reflector. Accordingly, the transmission line lengths are in the order of a quarter of the free space wavelength, in order to reach the ground-plane level, where load or source circuit are located. As an example, in the most standard design situation in which the periodicity of the array is about half wavelength, and the vertical lines are a quarter wavelength, two neighboring feeding lines and the electrical connection via the dipole constitute a one wavelength continuous electric path $(d x+2 l=\lambda)$ and create a strong cross-polarizing standing wave. The active input impedance for $d x=d y=15 \mathrm{~mm}, l=7.5 \mathrm{~mm}$, is shown in Fig. 7. In addition to the expected grating lobe and the guided pole resonances, a peak of the impedance appears at $10 \mathrm{GHz}$. By observing the vector current distribution, the resonance can be recognized as associated with common-mode distribution in the CPS lines (Fig. 8). According to the third definition of X-pol by Ludwig, [10], commonmode currents along $z$ radiate strong cross-polarized fields when scanning on the diagonal plane. In Fig. 10, the ratio between co-pol and X-pol fields rapidly increases in proximity of the resonance at $10 \mathrm{GHz}$. Therefore, to ensure low X-pol level, the length of the path $2 l+d_{x}$ should be significantly shorter than a wavelength in order to shift the common-mode resonances at higher frequencies, outside the operational bandwidth of the array.

\section{RESONANCE-FREE ARRAY DESIGN}

A CPStoCPS transformer, based on aperture coupling, has been designed to shorten the length of continuous current paths and reject common-mode propagation. A schematic view of the component is shown in Fig.

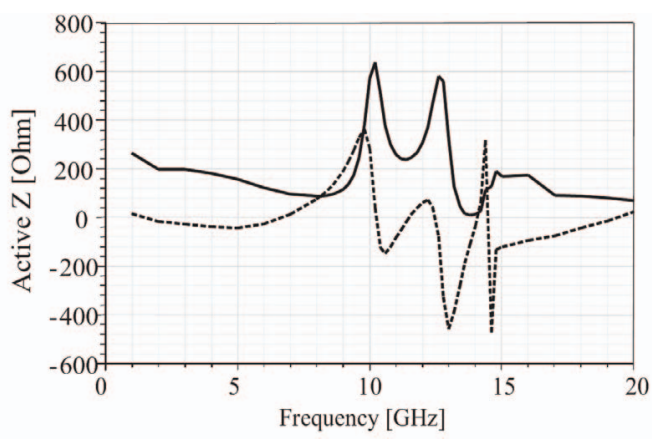

Figure 7: Real (-) and imaginary (- -) part of the active input impedance, when the array is scanning towards $\theta=45^{\circ}$ and $\varphi=45^{\circ}$.

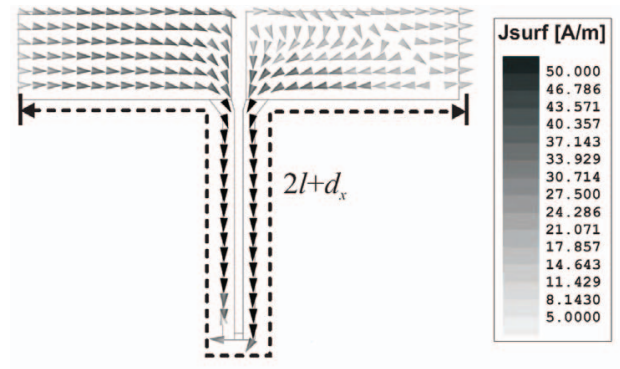

Fig. 9: Surface current distribution at $10 \mathrm{GHz}$.

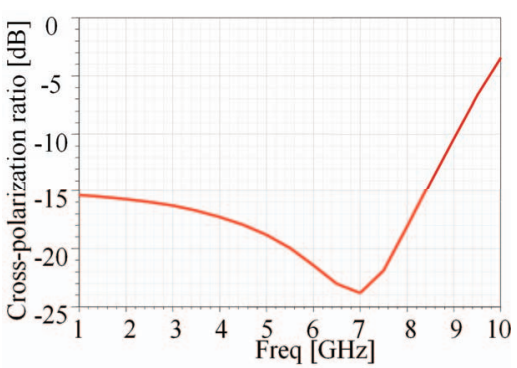

Fig. 10: X-pol level when pointing at $\theta=45^{\circ}, \varphi=45^{\circ}$.

11 , where the ground plane on which the slot is etched is assumed to be infinite along $x$. The component is divided in two parts separated by the ground plane. The part at $z=h$, here in after the primary circuit, comprises a transition from CPS lines to Grounded CPS (GCPS) lines, then a power divider that splits the circuit in two equal halves, which are eventually reconnected in correspondence of a coupling slot. The secondary circuit at $z=-h$ is the same as the primary, but mirrored with respect to the slot. The initial input from the CPS lines can be associated with a differential-mode or a common-mode type of current. The common mode in input corresponds to a zero of electric current in correspondence of the slot. In turn, this translates in no electric current being excited in the secondary circuit of the transformer.

The condition for high transmission levels of the differential mode is $Z_{\text {cell }}$ « $Z_{\text {slot }}$, where $Z_{\text {slot }}$ is the impedance of the slot and $Z_{\text {cell }}$ is the connected array 
element loading. Therefore, the bandwidth of the transformer is wider for low values of $Z_{\text {cell }}$. Normally, the input impedance of an evenly sampled array $\left(d_{x}=d_{y}\right)$ in the presence of a backing reflector is about $\zeta_{0} \approx 400 \Omega$. However, since $Z_{\text {cell }}$ is proportional to $d_{x} / d_{y}$, lower impedances can be obtained by considering a denser sampling of the array in the longitudinal direction. For example, with 4 feeds per cell $\left(d_{x}=\lambda_{0} / 8\right)$, the input impedance at each feed point becomes $Z_{\text {cell }}=\zeta_{0} / 4 \approx 100 \Omega$. The CPStoCPS or CPStoMS (balun) transitions can be made compact on high permittivity dielectric $\left(\varepsilon_{r}=10\right)$, and the same number on $\mathrm{T} / \mathrm{R}$ modules can be kept by means of power dividers (Fig. 12).

Fig. 13 shows the $\mathrm{X}$-pol ratio as a function of the frequency for the geometry depicted in Fig. 12. For an array designed to work until $10 \mathrm{GHz}$, the X-pol level remains lower than $-14 \mathrm{dBs}$ within the band of the array, while the common-mode resonance appears at a higher frequency $(11 \mathrm{GHz})$. This is because the path $p$, shown in Fig. 12, has an electric length shorter than one wavelength at the frequencies within the operational band of the array, avoiding the occurrence of resonances.

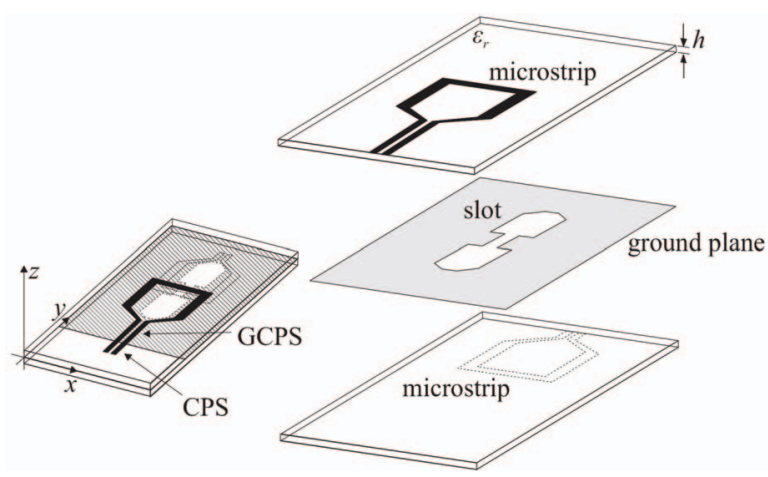

Fig. 11: Geometry of the transformer.

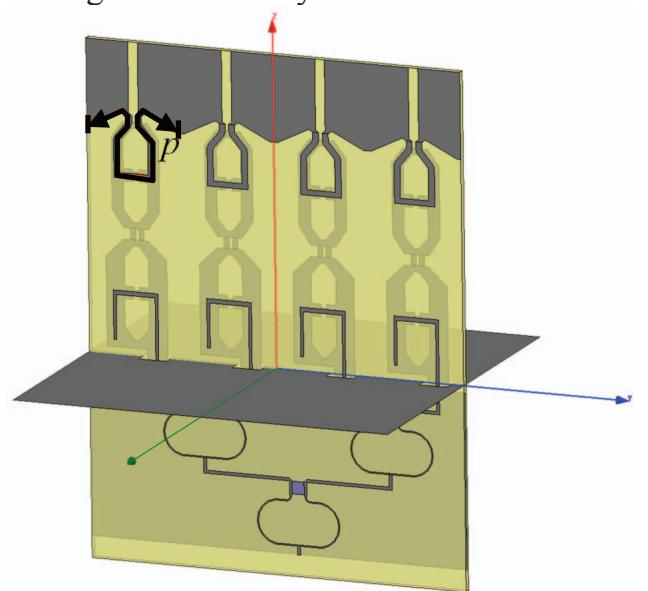

Fig. 12: Geometry of a unit cell of a connected array with periods $d_{x}=d_{y}=\lambda_{0} / 2$.

\section{References}

[1] Y. S. Kim and K. S. Yngvesson, "Characterization of Tapered Slot Antennas Feeds and Feed Array," IEEE Trans. Antennas and Propag., Vol. 38, pp. 1559-1564, Oct. 1990.

[2] M. C. van Beurden et al., "Analysis of WideBand Infinite Phased Arrays of Printed Folded Dipoles Embedded in Metallic Boxes," IEEE Trans. Antennas and Propag., Vol. 50, No. 9, pp. 1266-1273, Sep. 2002.

[3] M. A. Gonzalez et al., "Broad-Band CavityBacked and Capacitively Probe-Fed Microstrip Patch Arrays," IEEE Trans. Antennas and Propag., Vol. 48, No. 5, pp. 784-789, May. 2000.

[4] W. S. T. Rowe et al., "Performance of a Scannable Linear Array of Hi-Lo Stacked Patches," IEE Proc. Microw., Antennas and Propag., Vol. 150, No. 1, pp. 1-4, Feb. 2003.

[5] H. Wheeler, "Simple Relations Derived from a Phased Array Antenna Made of an Infinite Current Sheet" IEEE Trans. Antennas and Propag., Vol. 13, pp. 506-514, 1965.

[6] R. C. Hansen, "Linear Connected Arrays," IEEE Antennas and Wireless Propag. Lett., Vol. 3, 2004.

[7] A. Neto and J. J. Lee, "Ultrawide-Band Properties of Long Slot Arrays," IEEE Trans. Antennas and Propag., Vol. 54, No. 2, Feb. 2006.

[8] J. J. Lee et al., "Compact Light Weight UHF Arrays Using Long Slot Apertures," IEEE Trans. Antennas and Propag., Vol. 54, No. 7, July 2006.

[9] A. Neto et al., "Scanning Performances of Wide Band Connected Arrays in the Presence of a Backing Reflector," IEEE Trans. Antennas and Propag., in press.

[10] A. C. Ludwig, 'The Definition of Cross Polarization', IEEE Trans. Antennas Propag., Vol. AP-21, pp. 116-119, Jan. 1973.

[11] A. Neto et al., "Common Mode, Differential Mode and Baluns: the Secrets", $31^{\text {st }}$ ESA Antenna Workshop Proc., Noordwijk, the Netherlands, 1820 May 2009.

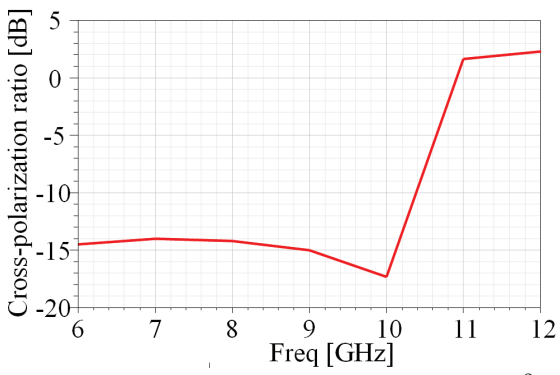

Fig. 13: X-pol level when pointing at $\theta=45^{\circ}, \varphi=45^{\circ}$, for the geometry in Fig. 12. 